\title{
Uma análise sobre a intensidade da racionalidade do mercado de capitais no intraday
}

Esta pesquisa, de natureza empírico-analítica, testa a eficiência de mercado e o comportamento do investidor, ao analisar, por meio de um estudo de caso, as ações do Banco Itaú Unibanco, após o anúncio de fatos relevantes junto à Comissão de Valores Mobiliários (CVM). A pesquisa se baseia em dados intradiários das ações ordinárias na tentativa de capturar a intensidade da racionalidade, no comportamento dos investidores no início do pregão após o anúncio, no nível de eficiência e no entendimento de informações relevantes dinâmicas e estáticas. Para a análise e comparação dos dados nos períodos ex-ante e ex-post, foi utilizada a metodologia de Estudo de Eventos, seguindo os procedimentos propostos por Mackinlay (1997). A principal contribuição da pesquisa está na análise do comportamento do movimento das ações durante o dia (intraday) para um único banco, uma vez que os estudos anteriores têm analisado o movimento intradiário de grupos de empresas ou então de carteiras de papéis de companhias. A predominância dos resultados sugere que determinados fatores como o efeito manada, a heurística de disponibilidade e a aversão à perda, foram caracterizados pela intempestividade e volatilidade anormal em comparação a janela de estimação fato que não assegura a existência de mercado eficiente nos minutos próximos da divulgação das informações relevantes selecionadas.

\section{An analysis of the intensity of capital market rationality in intraday}

This empirical-analytical research tests market efficiency and investor behavior by analyzing, through a case study, the shares of Banco Itaú Unibanco, following the announcement of material facts with the Brazilian Securities and Exchange Commission. (CVM). The research is based on intraday stock data in an attempt to capture the intensity of rationality, early investor behavior after the announcement, the level of efficiency and understanding of dynamic and static relevant information. For the analysis and comparison of data in the ex-ante and ex post periods, the Event Study methodology was used, following the procedures proposed by Mackinlay (1997). The main contribution of the research lies in the analysis of the behavior of intraday day-to-day stock movements, as previous studies have analyzed the intraday movement of groups of companies or company portfolios. The predominance of the results suggests that certain factors such as herd effect, availability heuristics and loss aversion were characterized by untimely and abnormal volatility compared to the estimation window - a fact that does not ensure the existence of an efficient market in the next few minutes. dissemination of selected relevant information.

Keywords: Intraday; Market efficiency; Rationality; Behavioral Finance.

Topic: Finanças Empresariais

Reviewed anonymously in the process of blind peer
Received: 03/04/2019

Approved: 05/06/2019
Alexandre Franco Godoi id

Pontifícia Universidade Católica de São Paulo, Brasil

http://lattes.cnpq.br/4704578926015219

http://orcid.org/0000-0002-4879-8520

godoi franco@hotmail.com

Carlos Élder Maciel de Aquino

Pontifícia Universidade Católica de São Paulo, Brasil

http://lattes.cnpq.br/5744834052232995

ce.aquino@uol.com.br

\section{Fernando de Almeida Santos}

Pontifícia Universidade Católica de São Paulo, Brasil

http://lattes.cnpq.br/4527505611889742

almeidasantos@pucsp.br
José Everardo Alves Pereira

Pontifícia Universidade Católica de São Paulo, Brasil

http://lattes.cnpq.br/8277330611317676

joseeverardo616889@gmail.com

José Odálio dos Santos

Pontifícia Universidade Católica de São Paulo, Brasil

http://lattes.cnpq.br/7018280423685826

http://orcid.org/0000-0001-6428-723X

j.odalio@pucsp.br

Referencing this:

GODOI, A. F.; AQUINO, C. E. M.; SANTOS, F. A.; SANTOS, J. O.;

MARION, J. C.. Uma análise sobre a intensidade da racionalidade do mercado de capitais no intraday. Revista Brasileira de Administração Científica, v.10, n.2, p.34-50, 2019. DOI:

http://doi.org/10.6008/CBPC2179-684X.2019.002.0003 


\section{INTRODUÇÃO}

A Teoria da Hipótese de Mercados Eficientes (HME) possui uma teoria geral, enquanto a Teoria de Finanças Comportamentais é composta por várias ideias que norteiam os fatores determinantes do comportamento das pessoas, o que torna difícil chegar a conclusões, mas gera base para busca do entendimento e poder explicativo dos fenômenos em Finanças. Um dos motivos de questionamentos são as ações dos tomadores de decisão que tem gerado resultados diferentes num mesmo ambiente macroeconômico. As duas correntes teóricas têm sido utilizadas em pesquisas e, dependendo do contexto e momento, observa-se que uma teoria pode ser capaz de explicar melhor que a outra.

Nos estudos realizados sobre a HME, Fama $(1970,1991)$ definiu a forma semiforte de eficiência, que posteriormente alterou seu nome para Estudo de Eventos. Não existe um único método científico para descrever os parâmetros de pesquisa da metodologia de Estudo de Eventos, mas em 1997 o Professor Mackinlay, da Universidade da Pensilvânia, nos Estados Unidos, criou um procedimento de condução do estudo científico que será a base para esta pesquisa.

A metodologia de estudo de eventos proposta por Mackinlay (1997) é utilizada nesta pesquisa para testar a teoria de mercados eficientes e a intensidade da racionalidade dos investidores, sendo ainda consideradas as abordagens comportamentais de Finanças. Diferentemente do modelo tradicional de estudo de eventos que faz uso de bases diárias, será utilizada uma base de dados com preços de negociações intradiários (intraday), a cada 15 minutos, de ações ordinárias do Banco Itaú Unibanco negociadas na [B] ${ }^{3}$ Brasil, Bolsa, Balcão, ou simplesmente [B] $]^{3}$, no período de 2013 a 2017.

Busca-se analisar, estatisticamente, o quanto a divulgação de um evento, nesse caso um fato relevante, influencia o comportamento do investidor no pregão da $[B]^{3}$ imediatamente posterior a sua divulgação, principalmente nas primeiras duas horas de pregão. Isso se dá porque as janelas de observação mais longas, com base nos fechamentos dos preços do dia ou do mês, não capturam a ampliação do retorno da ação ao redor da divulgação do evento, pois tende a normalização da volatilidade de preços e da intensidade do volume negociado da ação até o final do primeiro pregão pós-divulgação do evento.

Pelo exposto, esta pesquisa procura responder ao seguinte problema de pesquisa: O Mercado de Capitais demonstra eficiência, ou há variação na intensidade da racionalidade dos investidores, frente ao anúncio de fatos relevantes nas primeiras duas horas de pregão após o evento? Como objetivos da pesquisa, busca-se investigar quais comportamentos anormais são identificados logo após a divulgação de fatos relevantes, seus impactos no retorno, na volatilidade e no volume das ações, observando o movimento intradiário, e examinando os fundamentos da Teoria de HME e da Teoria de Finanças Comportamentais, por meio do uso de metodologia de Estudo de Eventos.

Para que os objetivos da pesquisa possam ser alcançados, são formuladas as hipóteses de pesquisa que permitem direcionar a investigação proposta neste estudo: Hipótese Nula $\left(\mathrm{H}_{0}\right)$ : Os eventos não contribuem para obtenção de retornos anormais; e Hipótese Alternativa $\left(\mathrm{H}_{1}\right)$ : Os eventos contribuem para obtenção de retornos anormais. Como limitações da pesquisa destacam-se alguns aspectos: a assimetria de 
informações; a própria metodologia de Estudo de Eventos por estar baseada na Teoria de HME; as negociações de grandes investidores com quantidades elevadas de ações negociadas durante o pregão; a possibilidade de zeragem de posição por parte dos investidores ao final do dia; o fato dos preços utilizados para a pesquisa contemplaram o horário das $10 \mathrm{~h}$ às $17 \mathrm{~h}$; e o uso do índice Ibovespa como proxy de mercado.

\section{REVISÃO TEÓRICA}

A compreensão sobre a dinâmica do Mercado Financeiro e a tentativa de prever seu comportamento tem sido um assunto relevante para os investidores, mas apenas recentemente o comportamento dos investidores tem sido levado em consideração como um fator explicativo. Fama (1970) considera que um mercado é eficiente quando os preços sempre refletem totalmente as informações disponíveis.

Uma de suas maiores contribuições foi definir três formas de eficiência de mercado, sendo a forma fraca, a forma semiforte e a forma forte. Na primeira forma, os preços refletem os retornos passados para predizer os retornos futuros. Na segunda forma, além dos preços históricos passados, estão refletidas nos preços dos títulos todas as informações públicas disponíveis de maneira rápida. Já na terceira forma, além dos retornos dos preços históricos e das informações disponíveis já contidas nos preços, somam-se a isso as informações que ainda não foram divulgadas, as quais são chamadas de informações privilegiadas.

Um contraponto ao conceito da HME é a Teoria do Prospecto, atualmente denominada de Finanças Comportamentais. Essa teoria diz respeito ao indivíduo, que é tomador de decisão e que nem sempre toma suas decisões com base em aspectos racionais (KIMURA et al., 2006). Nessa teoria, a decisão é tomada com base em diversos aspectos psicológicos inerentes às pessoas e suas características. Na verdade, em 1957, Simon já questionava a linha da racionalidade ligada às teorias tradicionais de finanças existentes à época, sob a argumentação de que o processo de tomada de decisão racional impede de constatar a real intenção do investidor (SIMON, 1957).

A Teoria do Prospecto, proposta por Kahneman et al. (1979), buscou explicar os vieses cognitivos ou heurísticos (atalhos mentais) durante o processo de tomada de decisão. Por meio de uma teoria sobre a utilidade esperada em condições de risco, Kahneman et al. (1979) procura explicar como os impulsos sensoriais se comportam, evidenciando que o processo de tomada de decisões não é apenas racional, principalmente quando o tempo disponível é limitado, pois os tomadores de decisões se utilizam de atalhos mentais nesse processo.

De acordo com Kahneman et al. (1979), a teoria da utilidade esperada hoje dominante, não incorpora elementos próprios da natureza humana que podem resultar em decisões errôneas. Um dos temas discutidos trata-se do Efeito Reflexão e Aversão a Perdas, onde os agentes tendem a serem avessos aos riscos diante de duas possibilidades de ganhos com a mesma utilidade esperada ou então tomadores de riscos quando as mesmas possibilidades se apresentam no domínio das perdas.

Segundo Kahneman (2012), existem três heurísticas ou atalhos mentais que possibilitam o julgamento de juízo de forma simples. A primeira é a heurística da representatividade, onde a representação de A para B é mais alta ou baixa se um é originado do outro ou não. A segunda é a heurística da 
disponibilidade que ocorre devido à frequência de algo na visão das pessoas, pois se elas veem, por exemplo, determinada notícia positiva, isso influenciará positivamente na sua tomada de decisão. Por fim, a terceira heurística é a de Ajuste ou Ancoragem, na qual as pessoas estimam começar por um valor inicial que é ajustado para produzir uma resposta final e a ancoragem se baseia no fato de que diferentes pontos de partida produzem estimativas diferentes e enviesadas na direção dos valores iniciais.

Outro tema discutido sobre o comportamento dos tomadores de decisões é o 'efeito manada', que vai de encontro à hipótese de que os preços se movimentam por um passeio aleatório. Para Silva et al. (2015), o 'efeito manada' ocorre quando um grupo de investidores negocia o mesmo ativo, na mesma direção do mercado, em certo período, ignorando suas próprias informações e crenças a respeito dos preços. Esse comportamento ou movimento de grupo é normalmente associado a movimentos exagerados de mercado, tais como, períodos de altas exageradas com compras frenéticas de ações (bolhas), ou de queda (crises), movidos por ganância e medo, respectivamente (BAKER et al., 2007).

Outro conceito é sobre a ausência de compreensão sobre aleatoriedade, que provoca a chamada falácia do apostador, ou seja, a crença de que uma ocorrência recente de certo resultado numa amostra de dados independentes provoca o aumento das probabilidades de determinados resultados diferente nas próximas ocorrências (MILANEZ, 2001). Neste contexto, os psicólogos econômicos não consideram irracionais as decisões econômicas tomadas pelos indivíduos, mas sim que a racionalidade é limitada, não ausente (SIMON, 1972). Por esse motivo, não é utilizado nessa pesquisa o termo irracionalidade, mas sim a intensidade da racionalidade, pois o investidor pode estar racional com menor ou maior intensidade.

A Metodologia de Estudo de Eventos tem a sua origem com os estudos de Dolley (1933) que analisou, no período de 1921 a 1931, os efeitos nos preços das ações em dias próximos à divulgação de 95 desdobramentos de ações (MACKINLAY, 1997). O tema teve destaque com os estudos de Ball et al. (1968) ao observarem que os erros ocorridos em informações contábeis entre as previsões e o realizado tinham impacto positivo no índice das ações quando divulgados próximo da data do anúncio do relatório anual. Essa metodologia é usada na área de finanças, principalmente, para medir como as informações sobre um determinado evento se comporta e seus reflexos nos retornos das ações.

Os eventos normalmente estudados abrangem as subscrições de ações, emissão de títulos de dívida (debêntures), lançamento de recibos de depósitos em outros mercados (DRs), bonificações, pagamento de dividendos, divulgações trimestrais, semestrais ou anuais de lucros, fusões e aquisições, vencimento de opções e desdobramentos de ações (CAMARGOS et al., 2003). O uso de dados do mercado financeiro possibilita analisar, por meio de estudo de eventos, o impacto de um evento específico no valor de determinada empresa (MACKINLAY, 1997). Em outras palavras, observa-se um evento, e verifica-se se há percepção de normalidade ao longo do tempo.

O Estudo de Eventos continua sendo uma metodologia importante de pesquisa na área de Finanças, de aplicação aparentemente simples, mas com pressupostos e requisitos críticos que se forem mal abordados, podem levar a falsas interpretações empíricas e teóricas (NAUMOVSKA et al., 2015). Com o avanço tecnológico, a metodologia ampliou seus horizontes e pesquisas têm sido feitas com periodicidade 
intradiário, que é conhecida na análise de dados de alta frequência. Segundo Dong et al. (2017), as atividades de negociação, geralmente, são em maior quantidade no início e no fechamento do dia de negociação e baixas no horário do almoço.

Quadro 1: Pesquisas que utilizaram como metodologia Estudo de Eventos no Brasil e Exterior.

\begin{tabular}{|c|c|c|}
\hline Autor(es) & Proposta da pesquisa & Síntese dos resultados \\
\hline $\begin{array}{l}\text { Patell et al. } \\
\text { (1984) }\end{array}$ & $\begin{array}{l}\text { Examinaram os efeitos no intraday dos anúncios de uma } \\
\text { agência de notícias sobre os ganhos de dividendos das ações } \\
\text { de } 96 \text { empresas, na sua maioria, listadas na Bolsa de Valores } \\
\text { de Nova York, sob três aspectos: retorno médio, variância de } \\
\text { retorno e correlação serial em mudanças de preços } \\
\text { consecutivos, no período de } 1976 \text { a } 1977 .\end{array}$ & $\begin{array}{l}\text { Identificaram que a reação dos preços aos ganhos e anúncios de } \\
\text { dividendos começou rapidamente nos primeiros minutos de pregão, o } \\
\text { maior retorno é constatado entre os } 5 \text { a } 15 \text { minutos após a divulgação } \\
\text { dos anúncios, mas perceberam que os testes não paramétricos } \\
\text { realizados não foram suficientes para outras conclusões, limitando os } \\
\text { resultados da pesquisa. }\end{array}$ \\
\hline $\begin{array}{l}\text { Wu et al. } \\
(1996)\end{array}$ & $\begin{array}{l}\text { Analisaram } 67 \text { desdobramentos de ações no período de } \\
1986 \text { a 1992, empresas listadas na Bolsa de Valores de Hong } \\
\text { Kong. }\end{array}$ & $\begin{array}{l}\text { Encontraram retornos excedentes ao longo dos três dias em torno do } \\
\text { anúncio dos desdobramentos. }\end{array}$ \\
\hline $\begin{array}{l}\text { Conroy et } \\
\text { al. (1999) }\end{array}$ & $\begin{array}{l}\text { Analisaram o desdobramento de } 5.264 \text { empresas listadas na } \\
\text { Bolsa de Valores de Nova lorque, no período de } 1925 \text { a } 1996 .\end{array}$ & $\begin{array}{l}\text { Observaram que os valores de Mercado dessas ações aumentaram } \\
\text { significativamente em torno das datas do anúncio dos desdobramentos } \\
\text { das ações. }\end{array}$ \\
\hline $\begin{array}{l}\text { Perobelli } \\
\text { et al. } \\
(2000)\end{array}$ & $\begin{array}{l}\text { Acessaram a questão da eficiência informacional em sua } \\
\text { forma semiforte, por meio dos preços das ações à } \\
\text { divulgação de lucros trimestrais que tenham sido } \\
\text { superestimados ou subestimados, divididos em três } \\
\text { categorias: notificas favoráveis, neutras ou desfavoráveis, } \\
\text { amostra de } 58 \text { companhias listadas na Bovespa, no período } \\
\text { de } 1997 \text { a } 1998 \text {. }\end{array}$ & $\begin{array}{l}\text { Concluíram que o mercado reagiu de forma rápida e instantânea ao } \\
\text { anúncio não antecipadas, promovendo retornos anormais positivos, } \\
\text { condizente com a forma semiforte de eficiência na carteira 1, na } \\
\text { carteira } 2 \text { percebeu retornos em excesso, o que não era esperado, esse } \\
\text { comportamento indicou que houve vazamento de informações e sobre } \\
\text { reação às informações divulgadas. }\end{array}$ \\
\hline $\begin{array}{l}\text { Kuse et al. } \\
\text { (2008) }\end{array}$ & $\begin{array}{l}\text { Analisaram } 120 \text { casos de desdobramento de ações na Bolsa } \\
\text { de Tóquio, anunciados durante } 2003 \text {, observaram } 30 \text { dias } \\
\text { úteis antes e após os anúncios, divididos em dois grupos } \\
\text { (menor que } 2 \text { para } 1 \text { e maior que } 2 \text { para } 1 \text { ). }\end{array}$ & $\begin{array}{l}\text { Descobriram que há excesso de retorno anormal cumulativo durantes } \\
\text { os } 30 \text { dias antes e após o anúncio dos desdobramentos, o grupo maior } \\
\text { que } 2 \text { para } 1 \text { observaram que um maior retorno após o anúncio, pico } \\
\text { com } 37 \text { dias úteis. }\end{array}$ \\
\hline $\begin{array}{l}\text { Kalay et al. } \\
\text { (2009) }\end{array}$ & $\begin{array}{l}\text { Testaram empiricamente o desdobramento de ações na } \\
\text { busca de retornos anormais e porque o mercado reage ao } \\
\text { anúncio dos desdobramentos de ações, na New York Stock } \\
\text { Exchange (NYSE), no período de } 1997 \text { a } 2001 .\end{array}$ & $\begin{array}{l}\text { Entenderam que existe uma relação entre o anúncio dos } \\
\text { desdobramentos e retornos anormais, observaram que os retornos } \\
\text { anormais foram significativamente maiores quando houve ganhos ou } \\
\text { anúncios de dividendos. }\end{array}$ \\
\hline $\begin{array}{l}\text { Galeno et } \\
\text { al. (2010) }\end{array}$ & $\begin{array}{l}\text { Analisaram se a contratação dos formadores de mercado } \\
\text { influenciou no preço e retorno das ações das empresas } \\
\text { contratantes, amostra de } 38 \text { empresas listadas na Bolsa de } \\
\text { Valores de São Paulo, no período de } 2007 \text { a } 2008 \text {, janela de } \\
\text { eventos de } 15 \text { dias antes e depois (-15 / DIA / +15); }\end{array}$ & $\begin{array}{l}\text { Mostraram que a absorção da informação pelo mercado não foi tão } \\
\text { rápida quanto era esperado, não houve indícios de vazamento de } \\
\text { informações, retornos anormais sem tendência definida e acumulados } \\
\text { negativos após a data zero, sugerindo que a contratação de formadores } \\
\text { de mercado é uma má noticia aos investidores que poderiam esperar } \\
\text { retornos desfavoráveis para essas ações; }\end{array}$ \\
\hline $\begin{array}{l}\text { Camargos } \\
\text { et al. } \\
(2015)\end{array}$ & $\begin{array}{l}\text { Analisaram o comportamento dos preços de ações de } \\
\text { companhias abertas brasileiras, nos dias próximos aos } \\
\text { anúncios de fusões e aquisições, buscando medir a eficiência } \\
\text { informacional semiforte, no período de } 1996 \text { a 2004, } \\
\text { utilizaram amostra de } 88 \text { ações, janela de eventos de cinco } \\
\text { dias (-5 / D / +5). }\end{array}$ & $\begin{array}{l}\text { Concluíram que o anúncio contém informações relevantes, observaram } \\
\text { indícios de uso de informações privilegiadas, o mercado se comportou } \\
\text { de forma eficiente, o mercado se comportou com queda para ações } \\
\text { preferenciais e com elevação para ações ordinárias. }\end{array}$ \\
\hline $\begin{array}{l}\text { Cruz et al. } \\
(2017)\end{array}$ & $\begin{array}{l}\text { Investigaram a eficiência e o comportamento das ações no } \\
\text { mercado norte americano e brasileiro que anunciaram e } \\
\text { concluíram acordos de joint venture, uma amostra de } 185 \\
\text { empresas, no período de } 2012 \text { a } 2017 \text {. }\end{array}$ & $\begin{array}{l}\text { Constataram que as ações não apresentaram desempenho anormal, } \\
\text { que as informações foram absorvidas de forma rápida e eficaz pelo } \\
\text { mercado, ou seja, houve eficiência semiforte pelo Mercado. }\end{array}$ \\
\hline $\begin{array}{l}\text { Ghadhab } \\
\text { (2017) }\end{array}$ & $\begin{array}{l}\text { Investigou os padrões de liquidez intradia ao redor da } \\
\text { ocorrência de uma oportunidade de arbitragem nos } \\
\text { mercados com dados de empresas europeias e canadenses } \\
\text { com ações listadas nos Estados Unidos. Estudou a relação } \\
\text { entre a liquidez e os preços das ações por meio de estudo de } \\
\text { eventos com frequência de } 15 \text { minutos de intervalo, no } \\
\text { período de } 07 \text { de agosto de } 2013 \text { a } 31 \text { de outubro de } 2013 \text {. }\end{array}$ & $\begin{array}{l}\text { A liquidez pareceu ser maior em todas as dimensões nas oportunidades } \\
\text { de arbitragem. Em vários casos, percebeu-se maior liquidez para a } \\
\text { janela que antecede a ocorrência do evento de arbitragem, isso } \\
\text { permitiu argumentar sobre a causalidade, que a discrepância de preço } \\
\text { para as ações entre as listas parecia ser a resposta para uma } \\
\text { determinada dinâmica de liquidez e atividade de negociação. Esta } \\
\text { arbitragem leva a concorrência entre os operadores, o que resulta em } \\
\text { aumento da liquidez e redução do spread. }\end{array}$ \\
\hline
\end{tabular}

Em seus estudos sobre o comportamento das ações do JP Morgan, entre janeiro de 2010 a abril de 2013, Dong et al. (2017) verificou que a volatilidade no início do pregão era aproximadamente duas a três vezes maiores que a próxima do final do pregão, em contraste, o número de transações no final do pregão era duas a três vezes maiores do que no período da manhã. $O$ quadro 1 apresenta pesquisas que utilizaram a aplicação da metodologia de estudo de eventos com a finalidade de capturar o efeito de divulgações informacionais sobre o retorno dos títulos de empresas. 
As instituições financeiras bancárias têm um papel fundamental no funcionamento dos sistemas econômicos, especialmente por sua função de intermediação financeira (BELÉM et al., 2016). O setor bancário no Brasil passou por transformações consideráveis nas últimas décadas, por consequência das mudanças na conjuntura econômica e política no país. A partir da década de 1970, teve início em vários países do mundo um processo de liberalização e desregulamentação do setor de serviços financeiros, onde gradualmente foram eliminando as restrições sobre operações financeiras, estabelecidas após a crise de 1929 e durante o regime de Bretton Woods (CAMARGO, 2009).

Ainda segundo o autor, a partir da segunda metade dos anos 1990, o processo de fusões e aquisições começou a acontecer entre grandes instituições, envolvendo volume significativo de recursos. A partir desse momento iniciou-se um processo de concentração bancária em vários países. No Brasil, segundo o BACEN (2018), dos 176 bancos, os 10 primeiros em termos de Ativos Totais representam 90\% de todo sistema bancário nacional.

Atualmente, são considerados como grandes bancos (ativo total) com atuação no varejo brasileiro e ações negociadas na [B] $]^{3}$ o Banco Itaú Unibanco, Banco Bradesco, Banco do Brasil e Banco Santander. Embora cada banco possua gestão e estratégia de negócios diferentes, eles podem ser comparáveis, mas com limitações. O Banco Bradesco e o Banco Itaú Unibanco são empresas privadas nacionais, enquanto o Banco Santander é uma empresa privada de capital estrangeiro e o Banco do Brasil é uma empresa de capital misto (privado e público).

O Banco Itaú Unibanco, objeto desta pesquisa, é o maior banco privado do Brasil considerando-se o montante de Ativos. Com ações negociadas na $[B]^{3}$, é uma companhia de capital aberto, multinacional brasileira, que em conjunto com empresas coligadas e controladas, atua no Brasil e no exterior, na atividade bancária em todas as modalidades por meio de suas carteiras comercial, de investimento, de crédito imobiliário, de crédito, financiamento e investimento e de arrendamento mercantil, inclusive as de operações de câmbio e nas atividades complementares, destacando-se as de Seguros, Previdência Privada, Capitalização, Corretagem de Títulos e Valores Mobiliários, Administração de Cartões de Crédito, Consórcios, Fundos de Investimentos e Carteiras Administradas.

No grupo econômico Itaú Unibanco (Itaú Unibanco Holding) encontra-se, dentre outras empresas, as marcas CorpBanca (Chile), Rede, Citi (Uruguai) e Citi Varejo (Brasil), Credicard, Recovery, Banco Itaú BMG Consignado, XP Investimentos, que estão presentes em 18 países além do Brasil, em atividades de banco comercial e operações de clientes institucionais, banco de investimentos, atacado e private banking, sendo que oito desses países estão na América Latina, além de ter presença na América do Norte, América Central, Europa, Ásia e Oriente Médio, conforme dados do Itaú Unibanco.

$\mathrm{O}$ Itaú Unibanco Holding tem suas ações negociadas na $[\mathrm{B}]^{3}$ Brasil, Bolsa, Balcão e está classificado no segmento especial de listagem da $[\mathrm{B}]^{3}$ como Nível 1 de Governança Corporativa, tendo a maior representatividade na composição do Índice Ibovespa com 10,23\% no ano de 2018 , muito embora apenas com ações preferenciais sendo negociadas e integrando o índice. Também possui American Deposity Receipt (ADRs) sendo negociadas na New York Stock Exchange (NYSE). 
No último relatório divulgado referente ao primeiro trimestre de 2018 , o banco tinha uma base de acionistas pulverizada, chamado de free float de $52,82 \%$ das ações ( $7,81 \%$ de ON e $99,57 \%$ de PN). O controle acionário com direito a voto (ON) está dividido entre Itaúsa (39,21\%), IUPAR $(51,71 \%)$, free float $(7,81 \%)$ e a tesouraria $(1,27 \%)$.

Tabela 1: Agregados patrimoniais do Itaú Unibanco Holding.

\begin{tabular}{|c|c|c|c|c|c|}
\hline Indicadores Itaú Unibanco Holding e controladas (em milhões de reais) & 2017 & 2016 & 2015 & 2014 & 2013 \\
\hline Produto Bancário & 111.050 & 118.661 & 92.011 & 91.657 & 79.387 \\
\hline Receita de Juros e Rendimentos & 144.690 & 161.495 & 147.789 & 120.115 & 94.127 \\
\hline Despesas de Juros e Rendimentos & -78.325 & -95.126 & -75.064 & -72.977 & -46.361 \\
\hline Receita de Dividendos & 301 & 288 & 98 & 215 & 205 \\
\hline Ganho (Perda) Líquido com Investimentos em Títulos e Derivativos & 3.175 & 7.311 & -11.862 & -724 & -5.924 \\
\hline Resultado de Operações de Câmbio de Transações no Exterior & -250 & 5.513 & -6.353 & 9.644 & 6.594 \\
\hline Receita de Prestação de Serviços & 34.448 & 31.918 & 29.452 & 26.342 & 22.712 \\
\hline $\begin{array}{l}\text { Resultado de Operações de Seguros, Previdência Privada e Capitalização antes das Despesas } \\
\text { com Sinistros e de Comercialização }\end{array}$ & 5.252 & 5.880 & 6.672 & 6.888 & 6.639 \\
\hline Receitas de Prêmios de Seguros e Previdência Privada & 26.914 & 24.849 & 22.634 & 22.797 & 23.327 \\
\hline Resseguros de Prêmios & 38 & 94 & 89 & -1.031 & -1.523 \\
\hline Variações nas Provisões de Seguros e Previdência Privada & -22.177 & -19.490 & -16.460 & -15.436 & -15.628 \\
\hline Receita de Operações de Capitalização & 553 & 615 & 587 & 558 & 463 \\
\hline Outras Receitas & 1.759 & 1.382 & 1.279 & 2.154 & 1.395 \\
\hline Perdas com Crédito e Sinistros & -18.240 & -22.122 & -21.335 & -15.801 & -14.870 \\
\hline Despesa de Provisão para Créditos de Liquidação Duvidosa & -20.746 & -24.379 & -24.517 & -18.832 & -17.856 \\
\hline Recuperação de Créditos Baixados como Prejuízo & 3.698 & 3.742 & 4.779 & 5.054 & 5.061 \\
\hline Despesas com Sinistros & -1.224 & -1.555 & -1.611 & -2.430 & -3.155 \\
\hline Recuperação de Sinistros com Resseguros & 32 & 70 & 14 & 407 & 1.080 \\
\hline Margem Operacional & 92.810 & 96.539 & 70.676 & 75.856 & 64.517 \\
\hline Outras Receitas/(Despesas) operacionais & -60.599 & -58.347 & -52.411 & -47.048 & -43.652 \\
\hline Despesas Gerais e Administrativas & -54.118 & -50.904 & -47.626 & -42.550 & -39.914 \\
\hline Despesas Tributárias & -7.029 & -7.971 & -5.405 & -5.063 & -4.341 \\
\hline \begin{tabular}{|l} 
Resultado de Participação sobre o Lucro Abrangente de Empresas não Consolidadas \\
\end{tabular} & 548 & 528 & 620 & 565 & 603 \\
\hline Lucro Líquido Antes de Imposto de Renda e Contribuição Social (LAIR) & 32.211 & 38.192 & 18.265 & 28.808 & 20.865 \\
\hline Imposto de Renda e Contribuição Social (Correntes) & -4.539 & -3.898 & -8.965 & -7.209 & -7.503 \\
\hline Imposto de Renda e Contribuição Social (Diferidos) & -3.404 & -10.712 & 16.856 & 262 & 3.160 \\
\hline LUCRO LÍQUIDO & 24.268 & 23.582 & 26.156 & 21.861 & 16.522 \\
\hline Lucro Líquido Atribuível aos Acionistas Controladores & 23.908 & 23.263 & 25.740 & 21.555 & 16.424 \\
\hline \begin{tabular}{|l|l|} 
Lucro Líquido Atribuível aos Acionistas não Controladores \\
\end{tabular} & 365 & 319 & 416 & 306 & 98 \\
\hline ON (Capital Social) em milhões de ações & 3.320 & 3.352 & 3.047 & 2.770 & 2.518 \\
\hline PN (Capital Social) em milhões de ações & 3.231 & 3.231 & 3.037 & 2.761 & 2.510 \\
\hline ON (Tesouraria) em milhões de ações & 14 & 0,003 & 0,003 & 0,003 & 0,002 \\
\hline PN (Tesouraria) em milhões de ações & 71 & 70 & 163 & 54 & 69 \\
\hline ON (Circulação) em milhões de ações & 3.306 & 3.352 & 3.047 & 2.770 & 2.518 \\
\hline \begin{tabular}{|l|} 
PN (Circulação) em milhões de ações \\
\end{tabular} & 3.159 & 3.161 & 2.874 & 2.707 & 2.441 \\
\hline Total em milhões de ações & 6.551 & 6.582 & 6.084 & 5.531 & 5.028 \\
\hline Preço de Fechamento (R\$̦/Ação ON) & 37,69 & 28,89 & 20,16 & 22,81 & 18,28 \\
\hline Preço de Fechamento (R\$̦/Ação PN) & 42,58 & 33,85 & 23,94 & 28,59 & 24,09 \\
\hline Valor da empresa a mercado (R\$ milhões) & 262.686 & 206.186 & 134.131 & 142.116 & 106.494 \\
\hline Valor de mercado / LAIR últimos 12 meses (R\$ milhões) & 8,16 & 5,40 & 7,34 & 4,93 & 5,10 \\
\hline Lucro líquido disponível para as ações ON (em milhões R\$) & 23.908 & 23.263 & 25.740 & 21.555 & 16.424 \\
\hline Média ponderada da quantidade de ações ON em circulação (em milhões) & 3.348 & 3.352 & 3.047 & 2.770 & 2.518 \\
\hline Lucro Líquido por ação ordinária em circulação (em R\$̣) & 7,14 & 6,94 & 8,45 & 7,78 & 6,52 \\
\hline Preço de Fechamento (R\$̦/Ação ON) & 37,69 & 28,89 & 20,16 & 22,81 & 18,28 \\
\hline Lucro por Ação ON em Circulação - Anualizado (em R\$) & 7,14 & 6,94 & 8,45 & 7,78 & 6,52 \\
\hline Índice P/L & 5,28 & 4,16 & 2,39 & 2,93 & 2,80 \\
\hline
\end{tabular}

Legenda: *Não está incluído o resultado do Itaú Unibanco Holding Prudencial.

Na tabela 1, observam-se os indicadores favoráveis de desempenho do Itaú Unibanco Holding, tais como os relacionados à receita de intermediação financeira, margem operacional, evolução do preço de fechamento da ação e Índice P/L. O valor de mercado da empresa tem crescimento vigoroso. Quando obtido o valor de mercado pelo LAIR, obtém-se um múltiplo com um salto em 2017 (de 5,40 em 2016 para 8,16 em 2017), que demonstra a força da marca e da estratégia da empresa. 


\section{METODOLOGIA}

A pesquisa é de natureza empírico-analítica, por utilizar de técnicas de coleta, tratamento e análise de dados quantitativos (MATIAS-PEREIRA, 2012). Esse tipo de pesquisa possui como característica privilegiar os estudos práticos, visto que suas propostas possuem caráter técnico, restaurador, incrementalista e forte preocupação causal entre as variáveis. O processo de validação da prova científica é feito por meio de testes dos instrumentos, graus de significância e sistematização das definições operacionais. Os dados foram adquiridos da plataforma de dados privada ESignal, que oferece dados de diversas Bolsas de Valores ao redor do mundo, inclusive dentre elas a $[B]^{3}$.

Concomitantemente, a estratégia de pesquisa está consubstanciada em Estudo de Caso e sua estratégia pede avaliação qualitativa, pois seu objetivo é o estudo de uma unidade social que se analisa profunda e intensamente (MARTINS et al., 2009). Ademais, a base metodológica para o estudo de eventos está nos procedimentos descritos por Mackinlay (1997), que também foram reescritos por diversos autores nacionais e internacionais.

Quadro 2: Passo a passo metodológico para o Estudo de Eventos.

\begin{tabular}{|l|l|}
\hline ETAPAS & DESCRIÇÃO \\
\hline Primeiro Passo & Definição do evento \\
\hline Segundo Passo & Critério de seleção \\
\hline Terceiro Passo & Medição dos retornos normais e anormais \\
\hline Quarto Passo & Procedimentos de estimativa \\
\hline Quinto Passo & Procedimentos de teste \\
\hline Sexto Passo & Resultados Empíricos \\
\hline Sétimo Passo & Interpretações e conclusões \\
\hline
\end{tabular}

O quadro 2 apresenta o passo a passo que Mackinlay (1997) utilizou. No primeiro passo está a definição do evento, ou seja, a data da ocorrência do evento, que é definida como 'data zero ou $D_{0}$ ', e o período no qual os preços das ações das empresas envolvidas serão examinados, ou seja, a janela de eventos que é subjetiva para o pesquisador.

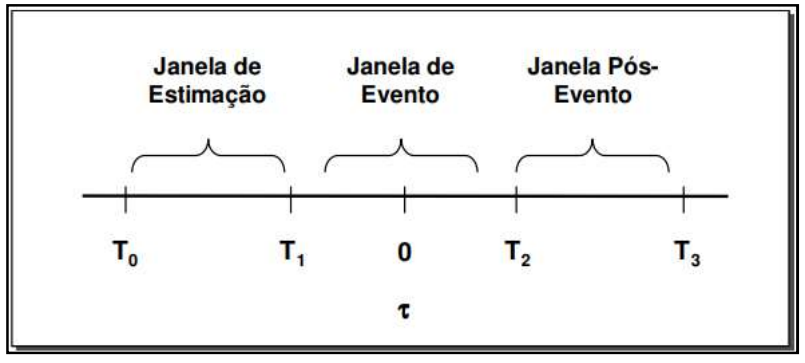

Figura 1: Linha do tempo de um estudo de eventos. Fonte: Mackinlay (1997).

A figura 1 demonstra a linha do tempo de um estudo de evento em relação à janela de evento. Seu número de observações não pode ser curto demais, de modo que não capture eventuais "vazamentos" de informações (insider information), ou longo demais, capturando oscilações anormais não relacionadas ao evento em questão.

No segundo passo é definido o critério de seleção, que deve cumprir requisitos mínimos para possibilitar a análise de desempenho. Dentre esses requisitos, considera-se que a empresa deve ter suas ações negociadas em Bolsa de Valores e precisa ter um nível mínimo de presença na bolsa (negociações) de 
pelo menos $80 \%$ durante a janela de evento, pois a baixa frequência leva a perda de liquidez. 0 outro requisito é que deve ter suas ações negociadas em datas antes e depois do evento. Isso é necessário para que se possa formar uma janela de estimação, que servirá de parâmetro para verificar se há retornos anormais no período a ser analisado.

O terceiro passo diz respeito ao modelo de medição dos retornos normais e anormais, buscando-se observar o impacto do evento nas ações das empresas selecionadas. O retorno observado da ação subtraído o retorno esperado é chamado de retorno normal para a mesma data, conforme pode-se observar na equação $A_{i, t}=R_{i, t}-E\left[R_{i} \mid X_{t}\right]$, onde $A_{i, t}=R_{i, t}-E\left[R_{i} \mid X_{t}\right]$ são, respectivamente, os retornos em excesso (retorno anormal), real e normal para a determinada ação no período t. Existem três métodos de medição dos retornos anormais, que são o modelo de retorno ajustado à média (ou a uma constante), o modelo de retorno ajustado ao mercado e, por fim, o modelo de mercado, esse último aquele que será utilizado na pesquisa.

O modelo de mercado é também conhecido como Ordinary Least Squares (OLS), ou Mínimos Quadrados Ordinários (MQO), e relaciona o retorno de uma determinada ação aos retornos de um portfólio de mercado. Esse último modelo é uma evolução dos demais, pois ao remover a porção do retorno da ação que ocorre em função do mercado a variância dos retornos anormais é reduzida, aumentando a possibilidade de se detectar os efeitos de eventos isolados. No entanto, os benefícios dependem do coeficiente de determinação do $R$ quadrado $\left(R^{2}\right)$ da regressão que, quanto maior, maior a qualidade do modelo. $O$ modelo pressupõe normalidade conjunta dos retornos dos ativos, linearidade, estacionaridade, independência dos resíduos em relação ao retorno de mercado e estabilidade da variância dos resíduos.

A equação $A_{i, t}=R_{i, t}-\widehat{\alpha}_{i}-\widehat{\beta}_{i} R_{m, t}$ apresenta o modelo de mercado, onde $\widehat{\alpha}_{i}$ e $\widehat{\beta}_{i}$ são valores OLS para o período estimado, ou seja, esses são os parâmetros da regressão linear envolvendo os retornos da ação e os retornos do mercado, calculados para o período da janela de estimação. O quarto passo é o procedimento de estimativa que deve ser realizado utilizando as observações da janela de estimação, e não deve incluir a data do evento (data zero), nem a janela de evento - período em que se acredita que já contenha algum tipo de influência nas negociações das ações, evitando que os parâmetros sejam influenciados pelo evento em si.

No quinto passo tem-se o procedimento de teste, onde a hipótese nula $\left(\mathrm{H}_{0}\right)$ deve ser definida, sendo que o evento não tem impacto sobre a média e variância dos retornos. A estatística de teste é a z, que para média igual a zero resume-se à razão entre a média do retorno em excesso para a janela do evento sobre o desvio padrão da janela de estimação. A Equação Teste: $\frac{A_{t}}{\sigma_{\left(A_{t}\right)}}$ a seguir apresenta o teste, onde $A_{t}$ é o retorno em excesso da janela de evento e $\sigma_{\left(A_{t}\right)}$ é o desvio padrão da janela de estimação. Uma hipótese estatística é a suposição sobre determinado parâmetro da população e o seu teste é um procedimento para decisão sobre a veracidade ou falsidade de determinada hipótese, mediante a utilização de uma amostra aleatória (FÁVERO et al., 2017). Por fim, o sexto e sétimo passos contemplam os resultados empíricos, interpretações e conclusões sobre os procedimentos anteriores. 
O método que será utilizado nesta pesquisa é o modelo de mercado descrito por Mackinlay (1997). Os eventos foram classificados e divididos em dois grupos. O primeiro grupo foi denominado de eventos dinâmicos, onde são considerados os eventos aguardados pelos analistas, acionistas e investidores, que nada mais são do que um evento com repetição sistemática de comportamento da empresa - um exemplo pode ser o processo repetitivo de recompra de ações baseado em planos de recompra anteriormente aprovados pelo Conselho de Administração. O outro grupo classificado é dos eventos estáticos, que são aqueles considerados inesperados e não recorrentes - um exemplo é o anúncio de uma aquisição, joint venture ou a saída do presidente da companhia.

A partir da ocorrência do evento inesperado, pode-se criar a expectativa de que ele venha a se repetir, ocorrendo pela segunda ou mais vezes. Um exemplo disso pode ser a divulgação de uma fusão da companhia (evento estático). A partir desse primeiro evento, os demais fatos relevantes sobre esse evento (fusão) serão considerados eventos dinâmicos. Dessa forma, o primeiro evento é um fato novo e do segundo evento ou mais eventos em diante, de mesma natureza ou desdobramentos do primeiro evento, os analistas, investidores e acionistas passam naturalmente a esperar outro evento, passando a ser um evento dinâmico.

No período utilizado para a pesquisa foram analisados 24 fatos relevantes em 22 datas. A lista de todos os fatos relevantes enviados à Comissão de Valores Mobiliários (CVM) nesse período é de 40 eventos, distribuídos em 33 datas. Foram excluídos os fatos relevantes que, ao longo de 21 dias posterior a sua publicação pela CVM, conflitavam com outro fato relevante divulgado. Dessa forma, buscou-se eliminar o risco de contaminação entre os eventos. Outros fatos relevantes foram excluídos, devido ter numa única data, dois ou três eventos com classificações diferentes (dinâmicos e estáticos), uma vez que não seria possível analisar o efeito da classificação separadamente e entre eles.

A classificação de eventos em dinâmicos ou estáticos é investigada na tentativa de se observar a existência de comportamento dispare entre os dois grupos. Busca-se capturar a reação do mercado e sua volatilidade nos primeiros momentos do pregão subsequente à divulgação e a cada fato relevante divulgado, e ainda mensurar a correlação existente entre os eventos classificados e entre os grupos (dinâmicos e estáticos). Na sequência, busca-se verificar o efeito dos fatos relevantes na demonstração do resultado do exercício do banco, se positivo ou negativo, e se há relação com o efeito do retorno das ações.

A inovação desta pesquisa encontra-se no fato de que a investigação é realizada utilizando-se um único banco para análise do comportamento do movimento das ações durante o dia (intraday), pois pelas observações realizadas, pode-se perceber que a academia tem analisado o movimento intradiário de grupos de empresas ou então de carteiras de papéis de companhias. $O$ dia do evento para esta pesquisa é definido como sendo o primeiro pregão após a divulgação do fato relevante. Houve casos em que o registro junto a CVM foi realizado após o fechamento do pregão, ou seja, à noite, de modo que o dia do evento a ser considerado será então o dia útil seguinte.

Em alguns casos, ocorreu do registro do fato relevante na CVM ter sido feito logo cedo, antes da abertura do pregão. Para esses casos, o dia do evento será o próprio dia do fato relevante. Ocorreram ainda 
outros casos em que o registro foi realizado durante o pregão. Nesses casos o dia do evento será o próprio dia do anúncio, sendo eles tratados como exceção pela CVM.

A medida de valor da ação é dada em reais, enquanto, para o caso do Ibovespa, a medida do índice é feita por pontos. Para que se pudesse comparar esses dados, as medidas foram transformadas em percentuais, dividindo-se o valor das ações do Banco Itaú Unibanco e a quantidade de pontos do Ibovespa pelos respectivos valores e quantidade anteriores, respectivamente.

Quadro 3: Descrição dos testes a serem realizados.

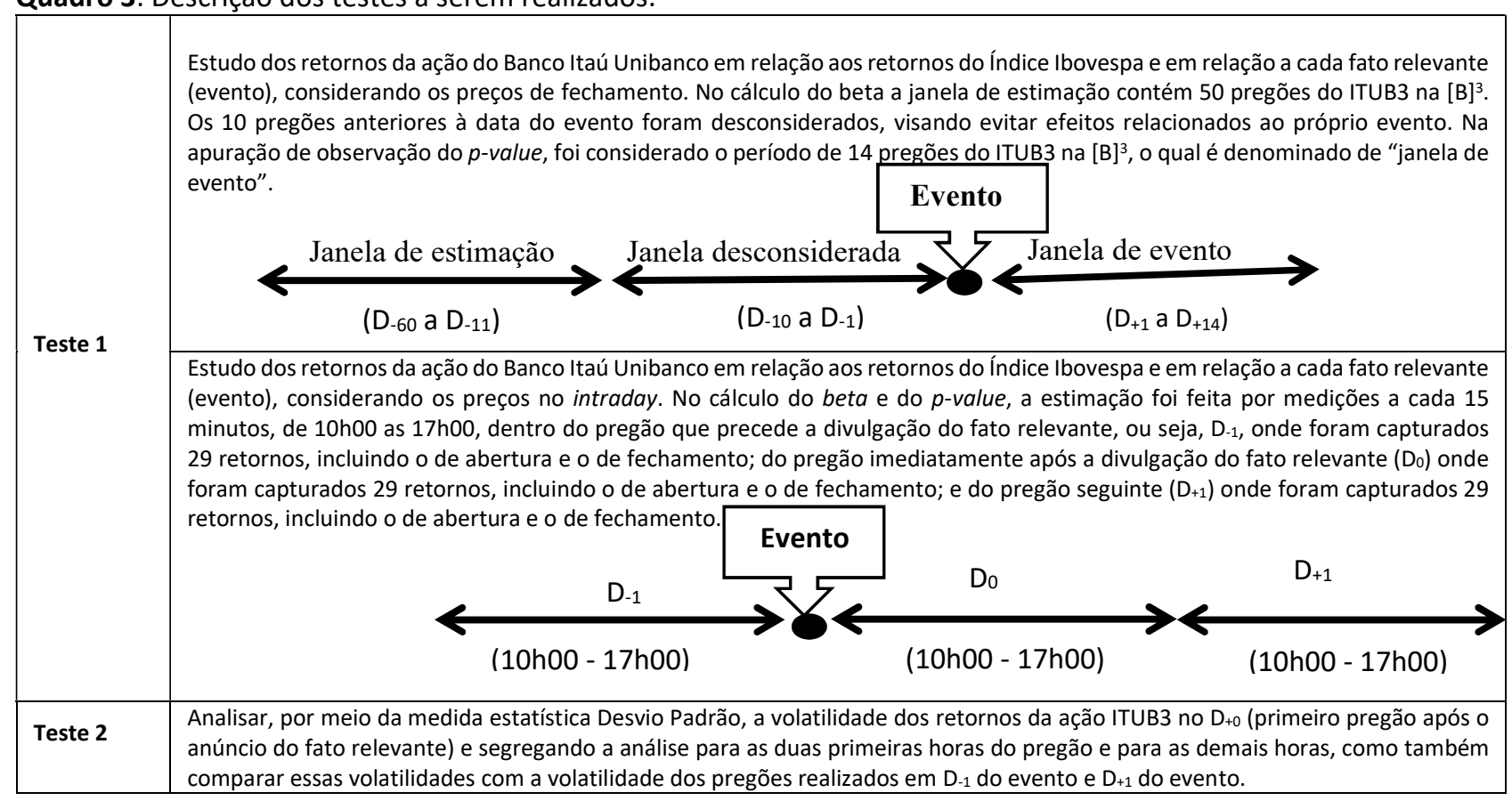

Conforme descrito no quadro 3, a primeira parte do teste 1 utilizará a metodologia tradicional descrita por Mackinlay (1997), enquanto a segunda parte apresenta como inovação da pesquisa a possibilidade de se observar os retornos, volatilidade e volumes negociados de uma empresa com ações negociadas na $[\mathrm{B}]^{3}$. O teste 2 efetua a análise da volatilidade.

\section{RESULTADOS E DISCUSSÃO}

\section{Teste 1: Comparativo dos retornos (ITUB3 X Ibovespa)}

Na primeira parte do teste, são analisados os retornos das ações do Banco Itaú Unibanco (variável dependente), comparando com os retornos do Ibovespa (variável independente), de forma relacionada a cada data com anúncio de fato relevante (evento). Para isso, foi considerada a variação do retorno dos preços de fechamento do dia de cada evento e calculado o coeficiente de determinação $\left(R^{2}\right)$ ajustado e o $p$-value por meio de regressão linear simples com o uso do Microsoft ${ }^{\circledR}$ Office Excel.

O coeficiente de determinação ajustado ( $R^{2}$ ajustado) é dado nesta pesquisa em percentual, podendo variar entre $0 \%$ e $100 \%$. Neste estudo, o $\mathrm{R}^{2}$ ajustado resulta o quanto o retorno dos preços de fechamento do Ibovespa explica o retorno dos preços das ações ordinárias (ITUB3) do Banco Itaú Unibanco. Já o p-value, que segundo Hoffmann (2016), é a probabilidade associada à cauda da distribuição, onde uma vez 
conhecendo essa probabilidade, basta compará-lo com o nível de significância adotado. Para esta pesquisa, o nível de significância estatística adotado é de 0,05 (5\%). Em outras palavras, o resultado será estatisticamente significativo sempre que a probabilidade caudal for igual ou menor do que o nível de significância.

Na segunda parte do teste, foram analisados os retornos tanto do Banco Itaú Unibanco como do Ibovespa no intraday (intervalo das 10h às 17h), foi observado o retorno dos preços a cada 15 minutos durante o pregão. A frequência de $15 \mathrm{~min}$ foi escolhida arbitrariamente, pois se desejava o menor intervalo possível. Observou-se também que se a escolha fosse por uma frequência menor, haveria muitos momentos sem negociação das ações, pois a liquidez é uma das premissas para a metodologia de estudo de eventos.

Nos intervalos onde não houve negociações das ações ordinárias do Banco Itaú Unibanco, repetiu-se o preço da última negociação, assim o retorno nesses casos foi igual à zero. Para esses casos, foi respeitado um dos requisitos da metodologia de estudo de eventos de ter no mínimo $80 \%$ de presença durante a janela de eventos, uma vez que nesta pesquisa, na amostra de 3 dias (dia anterior, dia do evento e posterior), foram verificados 87 eventos (29 eventos por dia), dos quais a menor presença foi de $80,46 \%$ durante uma janela de eventos. A tabela 2 apresenta o resultado do coeficiente de determinação ajustado ( $R^{2}$ ajustado) e o $p$ value dos retornos dos preços de fechamento e no intraday.

Tabela 2: Cálculo do $\mathrm{R}^{2}$ ajustado e $p$-value dos retornos com preços de fechamento e intraday do pregão.

\begin{tabular}{|c|c|c|c|c|c|}
\hline \multirow{2}{*}{ Data/hora do protocolo na CVM } & \multirow{2}{*}{ Característica } & \multicolumn{2}{|c|}{ Preço de Fechamento } & \multicolumn{2}{|c|}{ Intraday (intervalo de 15 minutos) } \\
\hline & & $R^{2}$ Ajustado & $p$-value & $\mathbf{R}^{2}$ Ajustado & $p$-value \\
\hline $13 / 12 / 2017-22 \mathrm{~h} 52$ & Estático & $53,50 \%$ & $75,00 \%$ & $4,90 \%$ & $39,90 \%$ \\
\hline 26/09/2017-13h27 & Dinâmico & $53,50 \%$ & $52,50 \%$ & $12,80 \%$ & $63,10 \%$ \\
\hline $31 / 08 / 2017-20 h 53$ & Dinâmico & $47,20 \%$ & $92,90 \%$ & $18,90 \%$ & $87,10 \%$ \\
\hline 31/07/2017-19h05 / 19h07 & Dinâmico & $78,00 \%$ & $93,10 \%$ & $26,20 \%$ & $53,10 \%$ \\
\hline $10 / 05 / 2017-07 \mathrm{~h} 00$ & Estático & $78,80 \%$ & $73,90 \%$ & $34,30 \%$ & $77,50 \%$ \\
\hline 07/02/2017-07h12 / 07h13 & Dinâmico & $78,80 \%$ & $56,90 \%$ & $39,70 \%$ & $13,90 \%$ \\
\hline 09/12/2016-19h02 & Dinâmico & $58,70 \%$ & $49,00 \%$ & $6,70 \%$ & $63,90 \%$ \\
\hline $08 / 10 / 2016-08 h 31$ & Estático & $58,50 \%$ & $34,30 \%$ & $26,30 \%$ & $95,10 \%$ \\
\hline $01 / 04 / 2016-18 h 30$ & Dinâmico & $63,80 \%$ & $71,20 \%$ & $45,00 \%$ & $62,00 \%$ \\
\hline $27 / 11 / 2015-08 h 31$ & Dinâmico & $57,50 \%$ & $56,80 \%$ & $7,90 \%$ & $93,40 \%$ \\
\hline $27 / 08 / 2015-18$ h07 & Dinâmico & $54,00 \%$ & $86,90 \%$ & $7,90 \%$ & $19,10 \%$ \\
\hline $04 / 08 / 2015-07 h 25$ & Dinâmico & $53,10 \%$ & $85,40 \%$ & $11,60 \%$ & $56,70 \%$ \\
\hline 03/06/2015 - 09h50 & Dinâmico & $59,80 \%$ & $79,10 \%$ & $40,50 \%$ & $98,90 \%$ \\
\hline 07/05/2015 - 20h34 & Dinâmico & $58,60 \%$ & $82,40 \%$ & $3,90 \%$ & $95,20 \%$ \\
\hline $27 / 11 / 2014-20 \mathrm{h00}$ & Dinâmico & $81,50 \%$ & $47,20 \%$ & $34,90 \%$ & $78,30 \%$ \\
\hline 05/08/2014-07h09 & Dinâmico & $69,20 \%$ & $75,80 \%$ & $11,10 \%$ & $58,40 \%$ \\
\hline $04 / 07 / 2014-10 h 49$ & Estático & $55,30 \%$ & $64,30 \%$ & $20,60 \%$ & $54,90 \%$ \\
\hline 29/01/2014-09h30 & Estático & $34,90 \%$ & $68,20 \%$ & $35,80 \%$ & $80,10 \%$ \\
\hline $28 / 11 / 2013-20 h 02$ & Dinâmico & $26,20 \%$ & $73,90 \%$ & $8,30 \%$ & $52,00 \%$ \\
\hline $30 / 07 / 2013-07$ h07 & Dinâmico & $41,30 \%$ & $56,70 \%$ & $33,00 \%$ & $38,30 \%$ \\
\hline $14 / 05 / 2013-18 h 59$ & Estático & $29,00 \%$ & $49,10 \%$ & $12,50 \%$ & $94,80 \%$ \\
\hline 05/02/2013 - 07h19 & Dinâmico & $8,40 \%$ & $8,30 \%$ & $8,00 \%$ & $98,80 \%$ \\
\hline
\end{tabular}

O $\mathrm{R}^{2}$ ajustado dos preços de fechamento variou entre $8,4 \%$ a $81,5 \%$, enquanto no intraday variou no mínimo de 3,9\% e no máximo em 45\%. Logo, o coeficiente de determinação indica que o comportamento do Ibovespa explica pouco ou quase nada, em alguns eventos, o comportamento das ações do Banco Itaú Unibanco, com mais veemência dos retornos no intraday.

Esse fato corrobora com o pensamento inicial, sendo ainda um motivador para a pesquisa, de que poderia existir um descolamento entre esses ativos objeto e a proxy de mercado nos momentos de anúncio de fatos relevantes por parte do Banco Itaú Unibanco, por se tratar de uma ação relevante no setor bancário 
dentro do Índice Ibovespa. O p-value elevado, acima do parâmetro limitador de 5\%, indica que não há significância estatística na amostra utilizada para esta pesquisa, significando, portanto, que o modelo proposto é adequado para prever o comportamento da variável dependente (ITUB3).

Embora questionáveis, os resultados sugerem que o lbovespa (variável independente) não influenciou, de forma estatisticamente significativa, o retorno das ações ordinárias do Banco Itaú Unibanco (ITUB3). Dessa forma, os retornos das ações ordinárias tiveram sua movimentação, em boa parte, independentes da movimentação do Ibovespa. Esse resultado vem ao encontro com a expectativa que se tinha previamente, uma vez que os números absolutos dos preços de fechamento já davam a entender uma divergência na intensidade das variações. Assim, os retornos dos preços das ações ordinárias do Banco Itaú Unibanco nas datas dos eventos analisados têm, em boa parte, independência em relação a proxy de mercado (Ibovespa).

\section{Teste 2: Volatilidade dos retornos no intraday}

Em seguida, no Teste 2, foi calculada a volatilidade do dia do evento por meio do desvio padrão, o dia anterior e posterior à divulgação do fato relevante pelo Banco Itaú Unibanco. Dessa forma, buscou-se observar o comportamento do dia do evento em relação ao dia anterior ao evento, bem como, o comportamento no dia após o evento. Logo após, foi calculada a volatilidade das primeiras duas horas do pregão pós-divulgação do fato relevante, para se verificar o comportamento no início do pregão e, por fim, foi também calculada a volatilidade das $12 \mathrm{~h}$ às $17 \mathrm{~h}$ (período da tarde). A tabela 3 tem por objetivo demonstrar o resultado do cálculo da volatilidade dos retornos dos preços das ações do Banco Itaú Unibanco.

Tabela 3: Volatilidade dos retornos dos preços das ações do Banco Itaú Unibanco.

\begin{tabular}{|c|c|c|c|c|c|c|}
\hline \multirow[t]{3}{*}{ Data/hora do protocolo na CVM } & \multirow[t]{3}{*}{ Característica } & \multicolumn{5}{|c|}{ VOLATILIDADE } \\
\hline & & \multirow[t]{2}{*}{$D_{-1}$} & \multicolumn{3}{|c|}{$D_{+0}$ (evento) } & \multirow[t]{2}{*}{$D_{+1}$} \\
\hline & & & Dia & $10: 00$ às $12: 00$ & $12: 00$ às $17: 00$ & \\
\hline $13 / 12 / 2017-22 \mathrm{~h} 52$ & Estático & $0,13 \%$ & $0,24 \%$ & $0,41 \%$ & $0,09 \%$ & $0,07 \%$ \\
\hline 26/09/2017-13h27 & Dinâmico & $0,09 \%$ & $0,11 \%$ & $0,18 \%$ & $0,07 \%$ & $0,08 \%$ \\
\hline $31 / 08 / 2017-20 h 53$ & Dinâmico & $0,10 \%$ & $0,10 \%$ & $0,11 \%$ & $0,08 \%$ & $0,07 \%$ \\
\hline 31/07/2017 - 19h05 / 19h07 & Dinâmico & $0,10 \%$ & $0,14 \%$ & $0,22 \%$ & $0,08 \%$ & $0,10 \%$ \\
\hline $10 / 05 / 2017-07 \mathrm{~h} 00$ & Estático & $0,13 \%$ & $0,14 \%$ & $0,23 \%$ & $0,07 \%$ & $0,11 \%$ \\
\hline 07/02/2017 - 07h12 / 07h13 & Dinâmico & $0,19 \%$ & $0,32 \%$ & $0,57 \%$ & $0,09 \%$ & $0,14 \%$ \\
\hline 09/12/2016-19h02 & Dinâmico & $0,10 \%$ & $0,22 \%$ & $0,38 \%$ & $0,10 \%$ & $0,13 \%$ \\
\hline 08/10/2016-08h31 & Estático & $0,15 \%$ & $0,15 \%$ & $0,26 \%$ & $0,06 \%$ & $0,08 \%$ \\
\hline $01 / 04 / 2016-18 \mathrm{~h} 30$ & Dinâmico & $0,22 \%$ & $0,13 \%$ & $0,20 \%$ & $0,09 \%$ & $0,17 \%$ \\
\hline $27 / 11 / 2015-08 h 31$ & Dinâmico & $0,15 \%$ & $0,17 \%$ & $0,12 \%$ & $0,20 \%$ & $0,22 \%$ \\
\hline $27 / 08 / 2015-18 \mathrm{~h} 07$ & Dinâmico & $0,31 \%$ & $0,23 \%$ & $0,34 \%$ & $0,17 \%$ & $0,34 \%$ \\
\hline $04 / 08 / 2015-07 h 25$ & Dinâmico & $0,20 \%$ & $0,15 \%$ & $0,22 \%$ & $0,11 \%$ & $0,17 \%$ \\
\hline 03/06/2015-09h50 & Dinâmico & $0,19 \%$ & $0,15 \%$ & $0,21 \%$ & $0,11 \%$ & $0,11 \%$ \\
\hline $07 / 05 / 2015-20 h 34$ & Dinâmico & $0,24 \%$ & $0,17 \%$ & $0,18 \%$ & $0,16 \%$ & $0,09 \%$ \\
\hline $27 / 11 / 2014-20 h 00$ & Dinâmico & $0,22 \%$ & $0,18 \%$ & $0,20 \%$ & $0,18 \%$ & $0,24 \%$ \\
\hline 05/08/2014-07h09 & Dinâmico & $0,12 \%$ & $0,23 \%$ & $0,36 \%$ & $0,12 \%$ & $0,16 \%$ \\
\hline $04 / 07 / 2014-10 h 49$ & Estático & $0,14 \%$ & $0,06 \%$ & $0,10 \%$ & $0,04 \%$ & $0,11 \%$ \\
\hline $29 / 01 / 2014-09 h 30$ & Estático & $0,16 \%$ & $0,17 \%$ & $0,24 \%$ & $0,12 \%$ & $0,17 \%$ \\
\hline $28 / 11 / 2013-20 h 02$ & Dinâmico & $0,13 \%$ & $0,16 \%$ & $0,09 \%$ & $0,19 \%$ & $0,15 \%$ \\
\hline $30 / 07 / 2013-07 h 07$ & Dinâmico & $0,14 \%$ & $0,34 \%$ & $0,58 \%$ & $0,14 \%$ & $0,21 \%$ \\
\hline $14 / 05 / 2013-18 h 59$ & Estático & $0,15 \%$ & $0,11 \%$ & $0,11 \%$ & $0,10 \%$ & $0,12 \%$ \\
\hline 05/02/2013-07h19 & Dinâmico & $0,14 \%$ & $0,19 \%$ & $0,21 \%$ & $0,17 \%$ & $0,14 \%$ \\
\hline \multicolumn{2}{|l|}{ Média Geral } & $0,16 \%$ & $0,17 \%$ & $0,25 \%$ & $0,12 \%$ & $0,14 \%$ \\
\hline \multicolumn{2}{|l|}{ Média Eventos Estáticos } & $0,14 \%$ & $0,14 \%$ & $0,22 \%$ & $0,08 \%$ & $0,11 \%$ \\
\hline \multicolumn{2}{|l|}{ Média Eventos Dinâmicos } & $0,16 \%$ & $0,18 \%$ & $0,26 \%$ & $0,12 \%$ & $0,15 \%$ \\
\hline \multicolumn{4}{|l|}{ Estáticos $\mathrm{D}_{0}$ (média) sobre $\mathrm{D}_{-1}$} & $55 \%$ & & \\
\hline
\end{tabular}




\begin{tabular}{|l|r|r|}
\hline Estáticos $D_{0}$ (média) sobre $D_{+1}$ & $102 \%$ & $58 \%$ \\
\hline Dinâmicos $D_{0}$ (média) sobre $D_{-1}$ & $69 \%$ & \\
\hline Dinâmicos $D_{0}$ (média) sobre $D_{+1}$ & \\
\hline
\end{tabular}

No dia do evento, que é após a divulgação do fato relevante, verificou-se que não houve tendência da volatilidade para maior ou menor em relação ao dia anterior e posterior na observação da volatilidade nos preços de fechamento. No que diz respeito à volatilidade das primeiras duas horas do pregão em comparação as demais horas desse dia, dos 22 eventos, apenas em 02 eventos a volatilidade das demais horas foi maior que as primeiras duas horas, logo após a divulgação do fato relevante. Observou-se assim que nas primeiras duas horas houve um comportamento mais intempestivo por parte dos investidores, o que demonstra menor intensidade na racionalidade nesses casos.

Uma possível explicação para isso pode estar relacionada ao efeito manada, onde os investidores caminham no mesmo sentido em grupo, mas sem eficiência, e ainda no curto espaço de tempo podem mudar de direção, resultando nesse efeito anormal. Outra possível explicação está na heurística de disponibilidade, pois há uma tendência de se acreditar que toda informação disponível tem maior probabilidade de se confirmar. No caso desta pesquisa, isso está relacionado ao anúncio dos fatos relevantes. Na figura 2 apresenta-se o gráfico do volume negociado, a cada 15 minutos, no dia 31/jul/2017 na [B] $]^{3}$.

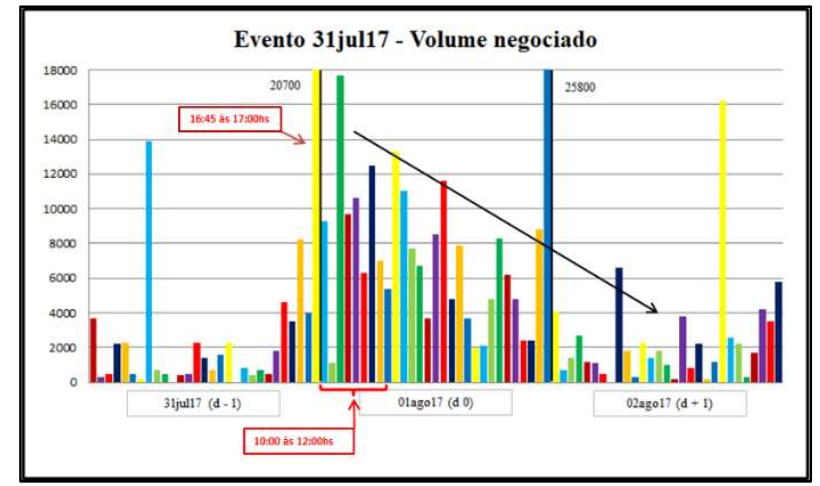

Figura 2: Gráfico do volume negociado a cada 15 minutos no dia 31/jul/2017.

As cores inseridas na figura 2 têm por objetivo melhorar a visualização. É possível visualizar a volatilidade que ocorreu nas primeiras duas horas e após as $12 \mathrm{~h}$, como também o grande volume negociado nos últimos 45 minutos. Nos últimos 45 minutos do dia anterior ao evento percebe-se um volume elevado de negociações. Foram 6,3 mil ações negociadas no corte das $16 \mathrm{~h} 15 \mathrm{~min}$ e 5 mil ações nos últimos 15 minutos, estando acima da média do dia que foi abaixo de 2 mil ações negociadas.

No dia do evento, as primeiras duas horas tiveram um volume expressivo de negócios, reduzindo o ímpeto de negociações ao longo do dia, após as duas horas iniciais do pregão. No dia seguinte ao evento, o volume negociado reduziu e percebe-se, com base na seta indicativa na figura 2 , que aos poucos foi entrando numa normalidade, ainda que com algumas negociações pontuais com maior volume.

Por outro lado, verificou-se que depois de ocorrido as primeiras duas horas de pregão ao longo do dia, a volatilidade diminuiu, na maioria dos casos de forma intensa, entrando assim numa normalidade em comparação a janela de estimação, com exceção de 02 dos 22 eventos pesquisados. Uma possível explicação está na Teoria de HME, onde a intensidade da racionalidade dos investidores aumentou após as duas horas 
iniciais, caracterizado pela redução da volatilidade das ações, tempo esse que os investidores levaram para assimilar os fundamentos diante do anúncio do fato relevante do banco.

Foram ainda calculadas as correlações existentes entre todos os eventos, no grupo de eventos dinâmicos e estáticos e com base nos retornos da ação, utilizando-se os preços de fechamento dos pregões e os preços da ação no intraday. A maioria das correlações ficaram entre 0 e $\pm 0,2$ (positivo ou negativo), demonstrando ser baixa a correlação dos retornos dos preços de fechamento e dos preços no intraday. Entre todos os eventos, os grupos dinâmicos e estáticos e os eventos com preços de fechamento e intraday, a correlação é baixa, não havendo relação entre esses eventos. Isso se deve, em parte, ao trabalho feito sobre a seleção dos eventos utilizados na pesquisa, uma vez que foi observado um prazo mínimo de 21 dias entre eles. Outra possível explicação para essa correlação baixa é que os eventos são isolados e o principal motivo é o anúncio dos fatos relevantes.

\section{CONCLUSÕES}

A presente pesquisa verificou quais comportamentos anormais são identificados logo após a divulgação de fatos relevantes pelo Banco Itaú Unibanco ao mercado de capitais, e seus impactos no retorno, na volatilidade e no volume das ações do banco, observando-se o movimento intradiário, a cada 15 minutos, e examinando-se os fundamentos da Teoria de HME e Teoria de Finanças Comportamentais, por meio do uso da metodologia de Estudo de Eventos.

Os eventos com características tanto estáticos como dinâmicos, demonstraram aumentar o volume negociado das ações do Banco Itaú Unibanco no primeiro pregão após o anúncio do fato relevante, em quatorze das vinte e duas datas de eventos em comparação ao dia anterior. Em outras palavras, em quatorze datas houve um tensionamento do volume para cima, o que leva a entender que o fato relevante foi condição para que isso pudesse ter ocorrido, sendo corroborado pela baixa influência do comportamento do Ibovespa no valor da ação do Banco Itaú Unibanco e evidenciado pelo $R^{2}$ ajustado baixo e $p$-value elevado.

Outro ponto a ser considerado, trata-se da volatilidade no retorno da ação, pois as duas primeiras horas de pregão após o anúncio do fato relevante foi, em média, 56\% maior que o dia anterior ao evento e $78 \%$ maior que o dia posterior ao evento, e quando comparado com as demais horas do primeiro pregão após o fato relevante, esse percentual aumentou para 108\%, ou seja, o dobro. Quando observado separadamente os eventos dinâmicos dos estáticos, nas primeiras duas horas de pregão foram observados que os eventos estáticos geraram $55 \%$ mais volatilidade no retorno da ação que o dia anterior e 102\% mais que o dia posterior, ou seja, o dobro. Mas, comparando-se as primeiras duas horas do pregão com as demais horas do dia do primeiro pregão após o fato relevante, essa relação passa para quase duas vezes, em média (1,75 vezes ou $175 \%)$.

Observando-se somente os eventos dinâmicos, as primeiras duas horas de pregão após o anúncio do fato relevante geraram volatilidade, em média, $58 \%$ maior no retorno da ação que o dia anterior e $69 \%$ mais que o dia posterior. Comparando-se as primeiras duas horas do pregão com as demais horas do dia do primeiro pregão após o fato relevante, essa relação passa a ser o dobro (1,16 vezes ou 116\%). 
A volatilidade do retorno da ação no dia do evento após o anúncio do fato relevante, comparada com os dias anterior e posterior, não são muito diferentes, pois se equivalem, mas conforme descrito quando observado as primeiras duas horas, foi consideravelmente maior. Esse aspecto gera evidências de que o fator comportamental do investidor foge ao padrão descrito na Teoria de HME nas primeiras duas horas, demonstrando menor intensidade da racionalidade dos investidores ao negociar as ações nos primeiros momentos após a ocorrência dos eventos.

Percebe-se que, após as primeiras duas horas de pregão, a volatilidade diminui e retorna aos níveis percentuais anteriores ao evento, demonstrando uma tendência de maior intensidade da racionalidade dos investidores, conforme a Teoria de HME. Observa-se também que os investidores são mais intensos e voláteis nas primeiras horas pós-divulgação do fato relevante, cujo comportamento não é observado quando analisado pela ótica tradicional de se considerar os retornos diários das ações. Assim, esta pesquisa justificase pelo tratamento do movimento intradiário, neste caso, a cada quinze minutos.

Com referência ao problema de pesquisa, determinados fatores como efeito manada, heurística de disponibilidade e aversão a perda, se confirmaram neste estudo, pois o curto espaço de tempo para se tomar a decisão de investir ou não, ficou caracterizado pela intempestividade e volatilidade anormal em comparação à janela de estimação. Assim, o mercado de capitais não demonstrou ser eficiente nas primeiras duas horas de pregão após os anúncios dos fatos relevantes.

Essa eficiência ocorre ao longo do dia, porém em alguns casos levou-se mais de um dia para entrar numa normalidade em comparação à janela de estimação. Após os investidores tomarem ciência das novas informações, leva-se um tempo para que se observe maior intensidade da racionalidade por parte desses investidores. Os resultados da pesquisa demonstram que a falta de um padrão de normalidade descaracteriza a Teoria de HME nas primeiras duas horas de pregão.

Sobre as hipóteses de pesquisa, os resultados obtidos levam à rejeição da hipótese nula $\left(\mathrm{H}_{0}\right)$, uma vez que os eventos contribuíram para a obtenção de retornos anormais, confirmando-se assim a hipótese alternativa $\left(\mathrm{H}_{1}\right)$. Para futuras pesquisas, sugere-se analisar empresas de outros setores dentro do Índice Ibovespa, a fim de se verificar se os comportamentos são diferentes dos apresentados nesta pesquisa. Por fim, outra sugestão é criar para os testes a serem aplicados uma proxy contendo empresas do próprio setor ao invés de se utilizar o Índice Ibovespa.

\section{REFERÊNCIAS}

BAKER, M.; WURGLER, J.. Investor sentiment in the stock market. The Journal of Economic Perspectives, v.21, n.2, p.129-151, 2007.

BALL, R.; BROWN, P.. An empirical evaluation of accounting income numbers. Journal of Accounting Research, v.6, n.2, p.159-178, 1968

BACEN. Banco Central do Brasil. Quantidade de instituições autorizadas a funcionar. Brasília: BACEN, 2018.

BELÉM, V. C.; GARTNER, I. R.. Análise empírica dos buffers de capital dos bancos brasileiros no período de 2001 a 2011.
Revista Contabilidade \& Finanças, v.27, n.70, p.113-124 2016.

CAMARGO, P. O.. A evolução recente do setor bancário no Brasil. São Paulo: Cultura Acadêmica, 2009.

CAMARGOS, M. A.; BARBOSA, F. V.. Eficiência informacional do mercado de capitais brasileiro em anúncios de fusões e aquisições. Revista de Administração da Universidade de São Paulo, v.25, n.3, p.571-584, 2015. 
CAMARGOS, M. A.; BARBOSA, F. V.. Estudo de Eventos: teoria e operacionalização. Caderno de Pesquisas em Administração, p.1-20, 2003.

CONROY, R. M.; HARRIS, R. S.. Stock splits and information: The role of share price. Financial Management, v.28, n.3, p.28-40, 1999.

CRUZ, I. F.; CARVALHO, G. A.; RIBEIRO, L. M. P.; MACIEL, C. F.; ARAÚJO, U. P.. Eficiência informacional de mercado em anúncios de criação de joint-ventures: um estudo de evento. In: SEMINÁRIOS DE ADMINISTRAÇÃO, 20. Anais. São Paulo: 2017.

DOLLEY, J. C.. Characteristics and procedure of common stock split-ups. Harvard Business Review, v.11, p.316-326, 1933.

DONG, Y.; TSE, Y. K.. Business time sampling scheme with applications to testing semi-martingale hypothesis and estimating integrated volatility. Econometrics, v.5, n.4, p.119, 2017.

FAMA, E. F.. Efficient capital markets II. Cambridge: The Journal of Finance, v.46, n.5, p.1575-1617, 1991.

FAMA, E. F.. Efficient capital markets: a review of theory and empirical work. Cambridge: The Journal of Finance, v.25, p.383-417, 1970

FÁVERO, L. P.; BELFIORE, P.. Manual de análise de dados. Rio de Janeiro: Elsevier, 2017

GALENO, M. M.; ROGERS, P.; PEREIRA, M. A.; FIORATTI, C. A.. $A$ influência dos formadores de mercado nos retornos das ações negociadas na Bovespa: um estudo de eventos. In: SEMINÁRIOS DE ADMINISTRAÇÃO, 13. Anais. São Paulo: 2010.

GHADHAB, I. Arbitrage opportunities and Liquidity: An intraday event study on cross-listed stocks. Journal of Multinational Financial Management, v.46, 2017

HOFFMANN, R.. Análise de regressão: uma introdução à econometria. Piracicaba: USP, 2016.

KAHNEMAN, D.. Rápido e devagar: duas formas de pensar Rio de Janeiro: Objetiva, 2012.

KAHNEMAN, D.; TVERSKY, A.. Prospect Theory: an analysis of decision under risk. Econometrica, v.47, n.2, p.263-290, 1979.

KALAY, A.; KRONLUND, M.. Stock splits: Information or liquidity. Illinois: University of Chicago, 2009.
KIMURA, H.; BASSO, L. F. C.; KRAUTER, E.. Paradoxos em Finanças: Teoria Moderna versus Finanças Comportamentais. Revista de Administração de Empresas, v.46, n.1, p.41-58, 2006

KUSE, Y.; YAMAMOTO, T.. Stock price anomalies subsequent to stock split announcements: Japanese evidences. SSRN Electronic Journal, Amsterdã, 2008.

MACKINLAY, A. C.. Event Studies in Economics and Finance. Journal of Economic Literature, v.25, n.1, p.13-39, 1997.

MARTINS, G. A.; THEÓPHILO, C. R.. Metodologia da investigação científica para ciências sociais aplicadas. 2 ed São Paulo: Atlas, 2009.

MATIAS-PEREIRA, J.. Manual de metodologia da pesquisa científica. 3 ed. São Paulo: Atlas, 2012

MILANEZ, D. Y.. Finanças comportamentais no Brasil. Dissertação (Mestrado em Economia) - Universidade de São Paulo, São Paulo, 2001

NAUMOVSKA, I.; JONG, A.. A note of event studies in finance and management research. Review of Finance, v.20, n.4, p.1659-1672, 2015.

PATELL, J. M.; WOLFSON, M. A.. The intraday speed of adjustment of stock prices to earnings and dividend announcements. Journal of Finance Economics, v.13, n.2, p.223-252, 1984

PEROBELLI, F. F. C.; NESS JUNIOR, W. L.. Reações do mercado acionário a variações inesperadas nos lucros das empresas: um estudo sobre a eficiência informacional no mercado brasileiro. In: ENCONTRO DA ASSOCIAÇÃO NACIONAL DOS PROGRAMAS DE PÓS-GRADUAÇÃO EM ADMINISTRAÇÃO. Anais. Florianópolis: 2000.

SILVA, J. X. S.; BARBEDO, C. H. S.; ARAÚJO, G. S.. Há efeito manada em ações com alta liquidez do mercado brasileiro?. Brasília: BACEN, 2015.

SIMON, H.. A behavioral model of rational choice. Quarterly Journal of Economics, v.69, p.99-118, 1957.

SIMON, H.. Theories of bounded rationality. In: MCGUIRE, C. B.; RADNER, R.. Decision and Organization: A Volume in Honor of Jacob Marschak. Amsterdam: North-Holland Publishing Company, 1972. p.161-176.

WU, L.; CHAN, B. Y. C.. Existence of an optimal stock price: Evidence from stock splits and reverse stock splits in Hong Kong. International Journal of Business, v.2, 1996.

A CBPC - Companhia Brasileira de Produção Científica (CNPJ: 11.221.422/0001-03) detém os direitos materiais desta publicação. Os direitos referem-se à publicação do trabalho em qualquer parte do mundo, incluindo os direitos às renovações, expansões e disseminacões da contribuiç̃o, bem como outros direitos subsidiários. Todos os trabalhos publicados eletronicamente poderão posteriormente ser publicados em coletâneas impressas sob coordenação da Sustenere Publishing da Companhia Brasileira de Produção Científica e seus parceiros autorizados. Os (as) autores (as) preservam os direitos autorais, mas não têm permissão para a publicação da contribuição em outro meio, impresso ou digital, em português ou em tradução. 